\title{
Bioaccumulation kinetics of copper in Ruditapes philippinarum exposed to increasing, continuous and pulsed exposure: Implications for growth
}

\author{
Lígia M.B.M. Santana a , Julián Blasco ${ }^{\mathrm{b}}$, Denis M.S. Abessa ${ }^{\mathrm{c}}$, Olivia Campana ${ }^{\mathrm{b}, *}$ \\ a Laboratório de Ecotoxicologia Marinha, Instituto de Ciências do Mar (LABOMAR), Universidade Federal do Ceará (UFC), Av. da Abolição, 3207, Meireles, 60165-081 Fortaleza, CE, Brazil \\ b Departamento de Ecología y Gestión Costera - Instituto de Ciencias Marinas de Andalucía (CSIC), Campus Rio San Pedro, 11510 Puerto Real, Cadiz, Spain

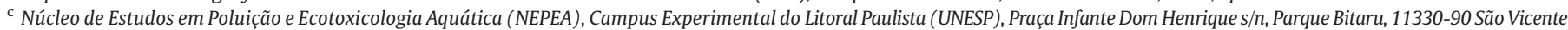 \\ SP, Brazil
}

\section{H I G H L I G H T S}

- Growth rate was inversely correlated to the net copper bioaccumulation rate.

- Large stimulatory effect on growth observed during the recovery period.

- Pulsed exposure has a more adverse effect compared to increased or continuous exposures.
GRA P H I C A L A B S T RACT

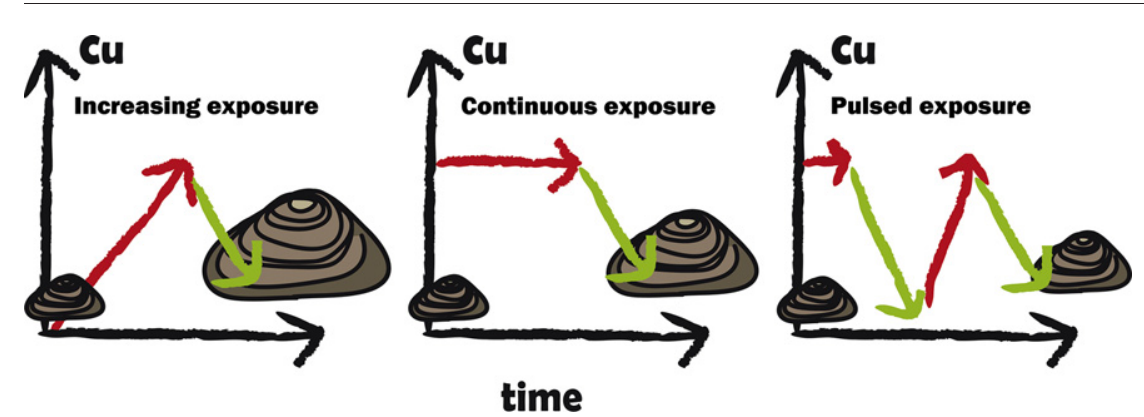

\section{A R T I C L E I N F O}

\section{Article history:}

Received 9 January 2017

Received in revised form 2 March 2017

Accepted 2 March 2017

\section{Keywords:}

Copper

Growth

Sediment

Bioaccumulation kinetics

Ruditapes philippinarum

\begin{abstract}
A B S T R A C T
Metal bioaccumulation and toxicity to aquatic organisms depends on factors such as magnitude, duration and frequency of the exposure. The type of the exposure affects the toxicokinetic processes in the organisms. In this study, we carried out 30-day toxicity tests on juveniles of Ruditapes philippinarum exposed to increasing, continuous and pulsed exposure. Organisms were exposed to copper-spiked sediments followed by a 10-day recovery period. We assessed the interaction between the kinetics of subcellular copper partitioning and the growth response. Results showed that the growth rate of the bivalve was inversely correlated to the bioaccumulation rate and that sublethal copper concentrations stimulated the detoxification mechanisms inside the organism regardless the type of the exposure. However, a large stimulatory effect on growth was observed during the recovery period, associated with significant negative accumulation rate values and dependent on the type of antecedent exposure. This suggested that on individual and short-term basis pulsed exposures have a more adverse effect compared to increasing or continuous exposure scenarios.
\end{abstract}

(c) 2017 Elsevier B.V. All rights reserved.

\section{Introduction}

Aquatic organisms are often exposed to metal contamination and the exposure can be continuous or episodic as a consequence of several activities, e.g. urban or domestic run-off, natural biogeochemical

\footnotetext{
* Corresponding author.

E-mail address: olivia.campana@icman.csic.es (O. Campana).
}

processing, application of agrochemicals, periodic release of industrial waste waters etc. The effect of the exposure will depend on its magnitude, duration and frequency and affect the toxicokinetic processes. These processes regulate the intracellular concentrations of metal ions into the organism, essential for the maintenance of life (George, 1982; Phillips and Rainbow, 1989). Very little is known about the bioaccumulation kinetics of metals and effects on the organisms during intermittent compared to continuous exposures (Amachree et al., 2013). 
Essential metals, like copper, can be regulated by limiting the metal uptake at the body concentration level, or by metal- and organism-specific accumulation strategies that include active elimination of the metal excess as well as its storage as an inert form (Rainbow, 2002; Rainbow et al., 2015; Vijver et al., 2004). The complexity of the internal metal binding supports the evidence that a tissue-residue approach based on the total tissue concentrations can fail to predict metal toxicity because metal compartmentalization within specific pools, such as extracellular (metal-rich granules) or intracellular (lysosomes, metallothionein-like proteins) structures, makes it possible to sequester metals in a detoxified form. Detoxification strategy typically varies depending on metal, e.g. copper has affinity to nitrogen or sulphur-containing chemical groups (Marigómez et al., 2002; Vijver et al., 2004), and organism but also depends on the field history of the organism itself, which can be subjected to chronic exposure (Giguère et al., 2003; Rainbow et al., 2015).

Characterization and kinetics of the subcellular distribution of metals have significant ecotoxicological implications because they will determine which fraction of metal is metabolically available and contributes to potential toxicity. Toxicity may commence if the metabolically available concentration exceeds the toxic threshold concentration that will occur when the metal influx rate exceeds the combined rate of detoxification and elimination (Rainbow and Luoma, 2011a; Simpson and King, 2005). This study was designed to gain more information and understanding about the different effects of continuous and intermittent exposures to metal contaminants and their implications on subcellular metal distribution. Thus, the aim of this work was to investigate the links between the kinetics of subcellular copper bioaccumulation and the growth response of Ruditapes philippinarum exposed to increasing, continuous and pulsed exposure to copper-spiked sediments and during a recovery period. This bivalve is an infaunal suspension feeder and was selected as test organism according to earlier studies (Chong and Wang, 2000; Fan and Wang, 2001) that have demonstrated that sediments often constitutes an important food source for this clam due to its resuspension.

\section{Materials and methods}

\subsection{Test organisms}

Ruditapes philippinarum (Adams and Reeve, 1850) is a native bivalve from the Indo-Pacific region introduced in Europe in the 1970s for commercial purposes and appreciated for human consumption (Delgado and Pérez-Camacho, 2007). This bivalve is an infaunal suspension feeder and earlier studies (Chong and Wang, 2000; Fan and Wang, 2001) have demonstrated that sediment often constitutes an important food source for this clam due to its resuspension. Juveniles of $R$. philippinarum (8-10 mm shell length) were purchased from an aquaculture farm (Amalthea, Cadiz), held in polypropylene tanks in a flow-through system and acclimated 7 days in a temperature controlled room (dissolved oxygen $10.1 \pm 4.1 \mathrm{mg} \mathrm{L}^{-1}, \mathrm{pH}_{\text {water }} 7.4 \pm 0.1$, temperature $19.0 \pm 0.6^{\circ} \mathrm{C}$, salinity $34.6 \pm 0.5$; means $\pm \mathrm{SD}$ ). Clams were fed twice a week ad libitum with Sera Micron powdered fish food (Fishtamins).

\subsection{Sediment collection and spiking}

Estuarine sediment was collected from a pristine site in the Bay of Cadiz (SW Iberian Peninsula; $36^{\circ} 23^{\prime} 31.80^{\prime \prime} \mathrm{N}, 6^{\circ} 12^{\prime} 24.01^{\prime \prime} \mathrm{W}$ ). At the time of collection sediment was press-sieved through a $1.0-\mathrm{mm}$ mesh to remove large debris and indigenous macrofauna and stored at $4{ }^{\circ} \mathrm{C}$ in the dark for up two weeks until spiking. Sediment at this location has been previously characterized and found to have low metal contamination (Campana et al., 2013a). After thorough homogenization, a subsample was used for the geochemical characterization including the determination of the particle size content ( $25 \%$ particles $<63 \mu \mathrm{m}$ ), particulate organic carbon content ( $2 \%$ OC) and bulk sediment copper concentration $\left(28 \mu \mathrm{g} \mathrm{Cu} \mathrm{g}{ }^{-1}\right)$. Because it has been demonstrated (Campana et al., 2013b; Campana et al., 2012; Strom et al., 2011) that the geochemical properties of the sediment affect copper bioavailability for deposit feeder species, these values were taken into account to yield OC-normalized copper spiking concentrations suitable to induce a sublethal effect without affecting the survival rate based on an previous, not published (O. Campana personal communication) study with $R$. philippinarum.

Sediments were spiked following the procedure described by Simpson et al. (2004). Briefly, copper sulphate pentahydrate $\left(\mathrm{CuSO}_{4} \cdot 5 \mathrm{H}_{2} \mathrm{O}\right)$ was prepared as an aqueous stock solution and added on a per dry weight basis to the sediment in order to yield three nominal copper concentration of 10 (low), 15 (medium) and 25 (high) mg Cu $<63 \mu \mathrm{m} \mathrm{g}^{-1}$ OC taking into account spike and background. Required amounts of stock solution were added on a sediment to water ratio 4:1 (v/v). Twenty-four hours after spiking, $\mathrm{pH}$ was measured (7.7 \pm 0.1 ; mean $\pm \mathrm{SD}$ ) and $\mathrm{pH}$ neutralization was considered unnecessary. Sediments were thoroughly mixed using a plastic spatula several times during the first week and then allowed to equilibrate for 30 days, at $4{ }^{\circ} \mathrm{C}$.

\subsection{Experimental design}

In order to study the effects of the different types of exposure, sublethal whole-sediment toxicity tests were conducted exposing clams to spiked sediments into $8 \mathrm{~L}$ polycarbonate tanks in a flow-through system, at flow rate of $130 \mathrm{~mL} / \mathrm{min}$, during 40 days and sampled at different times ( $\mathrm{T} 0=$ initial time, $\mathrm{T} 1=10$ days, $\mathrm{T} 2=20$ days, $\mathrm{T} 3=30$ days and $\mathrm{T} 4=40$ days). Sampling periods of 10 days were selected to obtain a sensitive measure of the juveniles' growth variation. At T0, 60 juvenile clams were separated from the batch, weighed and put into each tank. The average wet weight (tissue + shell) of the bivalves at T0 was recorded for each tank and used to calculate growth rate. Four treatments, each one tested in triplicate, were set up simultaneously with: (1) control, a group kept in unspiked sediment; (2) increasing exposure, where bivalves were subsequently exposed to increasing copper concentrations during 10 days each; (3) continuous exposure, where bivalves were maintained at the highest concentration for 30 days; and (4) pulsed exposure, where organisms were exposed to pulsed events by alternating the highest copper concentration and the control every 10 days. All trials ended after a recovery period (T4) of 10 days during which bivalves were exposed to the unspiked original sediment. Each 10 days, 10 clams were sampled from each replicate, allowed to depurate $24 \mathrm{~h}$ in natural clean seawater, weighed for growth analysis and soft tissues were pooled and frozen at $-80{ }^{\circ} \mathrm{C}$ until metal analysis. Throughout the experiments subsamples of sediment, pore and overlying water were collected to determine copper concentrations and physicochemical variables were recorded. Following the experimental design, tanks were set up (including sediment, water and aeration) two days before the shift of the bivalves for the next exposure to allow the equilibration of the physico-chemical conditions into the tank. The diet of the bivalves was supplemented with $1 \mathrm{mg}$ per tank of Sera Micron powdered fish food (Fishtamins) on alternate days.

\subsection{Sediment and water analyses}

All plastic and glassware were pre-cleaned by soaking in $10 \% \mathrm{HNO}_{3}$ (AR grade, Merk, Germany) for $24 \mathrm{~h}$ and rinsed with higher grade deionized water (Milli-Q, $18 \mathrm{M} \Omega \mathrm{cm}$, Millipore). Sediment particle size was determined by wet-sieving through a $63-\mu \mathrm{m}$ sieve using a minimum amount of deionized water followed by gravimetry. Particulate organic carbon (OC) content was determined by wet oxidation followed by titration using 888 Titrando analyzer (Metrohm, USA). Copper concentrations were analyzed in bulk sediment, in the $<63 \mu \mathrm{m}$ fraction and pore and overlying water. Sediment samples were oven dried at $60{ }^{\circ} \mathrm{C}$ for $24 \mathrm{~h}$ and digested according to the following procedure. Briefly, 
approximately $0.4 \mathrm{~g}$ of dried sediment and reference material MESS-3 (National Research Council Canada, NRCC) were digested using $9.0 \mathrm{~mL}$ $\mathrm{HNO}_{3}$ (Suprapur®, Merck, Germany), $5.0 \mathrm{~mL} \mathrm{HCl}$ (Suprapur®, Merck, Germany) and $2.5 \mathrm{~mL}$ HF (PlasmaPure Plus, SCP Science) in a MARS microwave oven (CEM, UK) and made up to $50 \mathrm{~mL}$ with $\mathrm{HBO}_{3}$ (Suprapur ${ }^{\circledR}$, Merck, Germany) 5.6\% (w/v). The pore water (PW) was extracted by centrifugation at $\sim 1,700 \times g(3500 \mathrm{rpm})$ for $10 \mathrm{~min}$. Both PW and overlying water (OLW) were membrane filtered through $0.45 \mu \mathrm{m}$ cellulose acetate (Sartorius Minisart, Sartorius, Goettingen, Germany) immediately after collection, acidified with concentrated $\mathrm{HNO}_{3}$ (Suprapur ${ }^{\circledR}$, Merck, Germany) $2 \%\left(\mathrm{v} / \mathrm{v}\right.$ ) and stored at $-20{ }^{\circ} \mathrm{C}$ until analysis. Overlying water copper concentrations $\left(\mathrm{dCu}_{\mathrm{OLW}}\right)$ were measured every 10 days. Pore water $\left(\mathrm{dCu}_{\mathrm{PW}}\right)$ and particulate sediment copper concentrations $\left(\mathrm{pCu}_{\text {sed }}\right)$ were assessed at $\mathrm{T} 0$ and at the end of the exposure for each sediment concentration, i.e. at T4 in the control experiment; at T1, T2, T3 and T4 in the increasing and pulsed exposure experiments; at T3 and T4 in the continuous experiment. Particulate and dissolved copper concentrations were determined by inductively coupled plasma optical emission spectrometry (ICP-OES Optima 2000 DV PE). For quality assurance, replicates were analyzed for all samples. Acid-digest blanks and certified reference material MESS-3 were run with each batch of samples. Copper concentration measured in reference material was $33.5 \pm 0.7 \mu \mathrm{g} \mathrm{g}^{-1}$ (mean $\pm \mathrm{SD} ; n=4$ ) dry mass and in good agreement with certified value $33.9 \pm 1.6 \mu \mathrm{g} \mathrm{g}^{-1}$ dry mass.

\subsection{Copper bioaccumulation and subcellular distribution analysis}

Tissue samples, each one composed by the pooled visceral mass of 10 bivalves of one replicate, collected at different sampling times ( $\mathrm{T} 0$, T1, T2, T3 and T4), were partially thawed on ice and manually minced with a blade. Subsamples of approximately $0.1 \mathrm{~g}$ (wet weight) were separated and frozen at $-20{ }^{\circ} \mathrm{C}$ to be analyzed for the total tissue residue copper concentration and to calculate the dry/wet weight ratio. The rest of the tissue (approximately $0.2 \mathrm{~g}$ wet weight) was homogenized on ice using a Pellet Pestle (Kontes) in $\mathrm{Ca} 2+/ \mathrm{Mg} 2+$ Free Saline Buffer (20 mM HEPES, $360 \mathrm{mM} \mathrm{NaCl}, 12.5 \mathrm{mM} \mathrm{KCl}, 5 \mathrm{mM}$ tetrasodium EDTA) adjusted at $\mathrm{pH} 7.4$ at $4{ }^{\circ} \mathrm{C}$; tissue-to-buffer ratios was adjusted at 1:6 (w/v). Tissue homogenate was subjected to differential centrifugation following a procedure adapted from Taylor and Maher (2012) that involved directly centrifuging the supernatant obtained from the first spin $\left(10 \mathrm{~min}, 1000 \times \mathrm{g}, 4^{\circ} \mathrm{C}\right)$ at $100,000 \times \mathrm{g}$ for $60 \mathrm{~min}$ at $4{ }^{\circ} \mathrm{C}$ to obtain a pellet fraction that included mitochondria, lysosomes and microsomes. Eventually, the entire procedure (Fig. S1 of Supporting Information (SI)) yielded three pellet fractions composed of heavy organelles (mitochondria, lysosomes and microsomes) (ORG), heatdenaturate proteins (HDP) which consist mostly of enzymes, metalrich granules (MRG) and two supernatant fractions composed of heatstable or metallothioneins-like proteins (MTLP) and nuclei and cellular debris (NCD). The subcellular partitioning was operationally classified and represented combining these fractions in two categories: the Biologically Available Metal (BAM) pool which included ORG and HDP fractions and the Biologically Detoxified Metal (BDM) pool that grouped MRG and MTLP fractions. As in other studies (Campana et al., 2015; Cooper et al., 2010; Liu et al., 2013), because the toxicological role of nuclei and cellular debris is still not clearly understood, NCD fraction was not included in either of these categories.

All fractions, including subsamples stored for total residue copper determination, were dried at $60{ }^{\circ} \mathrm{C}$ to a constant weight and digested in $1 \mathrm{~mL}$ conc. $\mathrm{HNO}_{3}$ (Suprapur®, Merck, Germany). Fish protein Certified Reference Material (DORM-2, National Research Council, Canada) and acid blanks were routinely digested simultaneously. Extracts were allowed to stand overnight and digested in a digester block (Analog Heatblock, VWR) at $90{ }^{\circ} \mathrm{C}$ for $2 \mathrm{~h}$. After addition of $0.2 \mathrm{~mL} \mathrm{H}_{2} \mathrm{O}_{2}$ (Merck, 30\%) digests were made up to $5 \mathrm{~mL}$ with Milli-Q and stored at $4{ }^{\circ} \mathrm{C}$ until metal analysis. Copper concentration measured in reference material was $2.40 \pm 0.32 \mu \mathrm{g} \mathrm{g}^{-1}$ (mean $\pm \mathrm{SD} ; n=8$ ) in agreement with certified value $2.34 \pm 0.16 \mu \mathrm{g} \mathrm{g}^{-1}$. Percentage recovery between the sum of the copper concentrations measured in the five fractions and the total copper tissue-residue concentration was $89 \pm 12 \%$ (mean $\pm \mathrm{SD} ; n=62$ ).

\subsection{Derivation of net accumulation and growth rates}

Different equations were applied to calculate rates considering that in the control, and partially, in the continuous exposure experiment (during the first 30 days) clams were exposed to steady conditions, whereas for other experiments these conditions changed each 10 days subjected to varied exposure. Net copper accumulation rate for total bioaccumulated, BDM and BAM copper pools was expressed as $\mu \mathrm{g} \mathrm{Cu}{ }^{-1}$ dry weight day ${ }^{-1}$ and was calculated by using the following equations. For the continuous exposure experiment (to calculate T1, T2 and T3) and for the control experiment:

Net accumulation rate ${ }_{i}, \mathrm{t}=\left(\left[\mathrm{Cu} \mathrm{pool}_{i}\right]_{\mathrm{t}}-\left[\mathrm{Cu} \mathrm{pool}_{i}\right]_{\mathrm{TO}}\right) / \mathrm{t}$

For increasing and pulsed exposure experiments and for the continuous exposure experiment (to calculate T4):

Net accumulation rate $_{i \mathrm{t}}=\left(\left[\mathrm{Cu} \operatorname{pool}_{i}\right]_{\mathrm{t}}-\left[\mathrm{Cu} \operatorname{pool}_{i}\right]_{\mathrm{t}-10}\right) / 10$

where, $i$ is either the total net bioaccumulated copper, BDM or BAM copper pool; $t$ is the time in days $(10,20,30$ or 40 corresponding to the sampling times); $\left[\mathrm{Cu} \text { pool }_{i}\right]_{\mathrm{t}},\left[\mathrm{Cu} \operatorname{pool}_{i}\right]_{\mathrm{To}}$, and $\left[\mathrm{Cu} \text { pool }_{i}\right]_{\mathrm{t}-10}$ are the copper concentrations of the specific pool measured at time $\mathrm{t}$, at time 0 and 10 days before the time $t$, respectively $\left(\mu \mathrm{g} \mathrm{g}^{-1}\right)$.

Growth rate for $R$. phillipinarum was expressed as mg wet weight day $^{-1}$ and was calculated by using the following equations. For the continuous exposure experiment (to calculate T1, T2 and T3) and for the control experiment:

growth rate T $=\left(\mathrm{G}_{\mathrm{T}}-\mathrm{G}_{\mathrm{T} 0}\right) / \mathrm{t}$

For increasing and pulsed exposure experiments and for the continuous exposure experiment ( to calculate T4):

growth rate $_{\mathrm{T}}=\left(\mathrm{G}_{\mathrm{T}}-\mathrm{G}_{\mathrm{t}-10}\right) / 10$

where, $\mathrm{t}$ is the time in days $(10,20,30$ or 40 corresponding to the sampling times); $\mathrm{G}_{\mathrm{T}}, \mathrm{G}_{\mathrm{T} 0}$, and $\mathrm{G}_{\mathrm{T}-10}$ are the average weights of the bivalves measured at time $t$, at time 0 and 10 days before the time $t$, respectively, expressed as mg wet weight.

\subsection{Statistical analyses}

Data were tested for normality of distribution and homogeneity of variance (Bartlett's test) prior to null hypothesis testing. Means within and between treatments were compared using One Way Analysis of Variance (F-ratio) or Kruskall-Wallis tests $(H$-test) when statistical assumptions (normality and homoscedasticity) to run the parametric test failed. A post hoc Pairwise Multiple Comparison test based on Fisher's least significant (LSD) procedure was performed to compare between groups when the main test revealed statistical significant difference. Spearman rank order correlations $(\rho)$ were determined between the total bioaccumulated copper variable $\left(\mathrm{Cu}_{\text {bio }}\right)$ and particulate $\left(\mathrm{pCu}_{\text {sed }}\right)$ and dissolved copper $\left(\mathrm{dCu}_{\mathrm{PW}}, \mathrm{dCu}_{\mathrm{OLW}}\right)$ concentrations; they were also applied to check the strength of the correlation between growth rate and total bioaccumulated copper, BDM and BAM rates. Statistical significance was set at $p \leq 0.05$. Statistical tests were carried out using Statgraphics Centurion XVII (Statpoint Technologies, Inc.) computer software. 


\section{Results and discussion}

\subsection{Physicochemical test conditions and copper partitioning}

Table S1 of SI summarized values of the physicochemical variables and copper partitioning in the particulate and dissolved phases for each toxicity test.

Copper concentrations, after sediment spiking and equilibration, were measured before starting the experiments and were found 12.1, 19.2 and $24.7 \mathrm{mg} \mathrm{Cu}<63 \mu \mathrm{m} \mathrm{g}^{-1}$ OC, for low, medium and high exposure respectively, representing environmentally relevant concentrations for relatively low contaminated sediments. Copper concentration in the unspiked sediment was $2.1 \mathrm{mg} \mathrm{Cu}<63 \mu \mathrm{m} \mathrm{g}^{-1} \mathrm{OC}$, in agreement with the value of $3.5 \mathrm{mg} \mathrm{Cu}<63 \mu \mathrm{m} \mathrm{g}^{-1}$ OC proposed by Simpson et al. (2011) that is proposed to provide suitable protection against the chronic effects of copper to benthic invertebrates in marine environments.

Measured $\mathrm{dCu}_{\mathrm{pw}}$ at $\mathrm{T} 0$ and during the experiments were all below $8.0 \mu \mathrm{g} \mathrm{Cu} \mathrm{L}{ }^{-1}$. This value was close to that typically measured for naturally contaminated sediment (i.e. $<5 \mu \mathrm{gu} \mathrm{L}^{-1}$ ) (Bat and Raffaelli, 1998; Simpson et al., 2011) indicating that equilibration procedure was adequate, allowing the binding of most of the spiked copper to the particulate phase. In the experiments, $\mathrm{dCu}_{\mathrm{PW}}$ were found mostly lower than $\mathrm{dCu}_{\mathrm{OLW}}$ in all toxicity tests. Most of the $\mathrm{dCu}_{\mathrm{OLw}}$ values were lower than the chronic $\mathrm{EC}_{50}$ of $9.2 \mu \mathrm{g} \mathrm{Cu} \mathrm{L}^{-1}$ calculated by Simpson et al. (2011) using a Species Sensitivity Distribution approach, and did not exceed $20 \mu \mathrm{g} \mathrm{Cu} \mathrm{L}{ }^{-1}$. This value was also below the $\mathrm{LC}_{50 \mathrm{~s}} 45 \pm 10$ and 33 $\pm 2 \mu \mathrm{g} \mathrm{Cu} \mathrm{L}{ }^{-1}$ calculated for other bivalves, Spisula trigonella and Tellina deltoidalis, respectively, in 10-d whole-sediment toxicity tests (Strom et al., 2011). Partition coefficients, $K_{d}$, which describe sediment-water partitioning distribution at steady-state conditions $\left(\mathrm{K}_{\mathrm{d}}\left[\mathrm{L} \mathrm{kg}^{-1}\right]=\mathrm{Cu}\right.$ sediment $\left[\mathrm{mg} \mathrm{kg}^{-1}\right] / \mathrm{Cu}$ water $\left[\mathrm{mg} \mathrm{L}^{-1}\right]$ ), ranged from $2.8 \times 10^{3}$ to $3.6 \times 10^{4} \mathrm{~L} \mathrm{~kg}^{-1}$ for OLW and from $7.1 \times 10^{3}$ to $2.6 \times 10^{4} \mathrm{~L} \mathrm{~kg}^{-1}$ for PW. These $K_{d}$ values are comparable to those commonly measured for copper in marine and estuarine sediments, which typically range from $1 \times 10^{3}$ to $5 \times 10^{5} \mathrm{~L} \mathrm{~kg}^{-1}$ (Hutchins et al., 2008), and indicate low dissolved copper concentrations for naturally contaminated environments. Metals in the dissolved phase are usually more bioavailable than particulate metals, thus partition coefficient is an important factor to predict the bioaccumulation within aquatic biota (Ahlf et al., 2009; Fukunaga and Anderson, 2011).

Average physicochemical variables during the experiments were as follows: $\mathrm{pH}_{\text {water }} 8.3 \pm 0.1, \mathrm{pH}_{\text {sediment }} 7.4 \pm 0.1$, dissolved oxygen 8.9 $\pm 2.9 \mathrm{mg} \mathrm{L}^{-1}$, salinity $35.0 \pm 0.8$ and temperature $17.8 \pm 2.0^{\circ} \mathrm{C}$ (mean $\pm \mathrm{SD} ; n=60$ ). In control treatment survival rate was $100 \%$ and remained $>80 \%$ for all exposures meeting testing acceptability criteria.

\subsection{Influence of dissolved and particulate phase on copper bioaccumulation}

It is becoming increasingly accepted that metal uptake from dissolved phase is not the only significant source of bioaccumulation for aquatic organisms (Croteau and Luoma, 2009; DeForest and Meyer, 2015). Bioaccumulation kinetics depend on the contribution of both particulate and dissolved exposure pathways and are strongly influenced by the feeding habit of the species. Thus, correlations between bioaccumulated copper and particulate and dissolved copper concentrations were assessed to establish the relative importance of the exposure pathway on copper bioaccumulation for $R$. philippinarum. Particulate (sediment) and dissolved copper concentrations during the experiments as well as total bioaccumulated copper $\left(\mathrm{Cu}_{\text {bio }}\right)$ concentrations are presented in Figs. 1 and 2.

As expected bioaccumulated copper concentrations were relatively steady in the control experiment with an average value of $11.4 \pm 1.5$ $\mu \mathrm{g} \mathrm{g}^{-1}$ (mean $\pm \mathrm{SD}$ ) and varied over time in the different treatments reaching a maximum of $43.8 \mu \mathrm{g} \mathrm{g}^{-1}$ in the pulsed exposure experiment. A significant strong correlation was observed between $\mathrm{Cu}_{\text {bio }}$ and $\mathrm{dCu}_{\text {olw }}(\rho=0.73, p<0.001, n=42)$ while the correlation between $\mathrm{Cu}_{\text {bio }}$ and $\mathrm{dCu}_{\mathrm{PW}}$ was not significant $(\rho=0.34, p>0.05, n=29)$. The low contribution of $\mathrm{dCu}_{\mathrm{PW}}$ to copper bioaccumulation was not surprising because, according to other studies with different species, it was observed that the exposure to dissolved copper occurs almost entirely from the overlying water and that the feeding behaviour of the species plays an important role (Campana et al., 2013b; Campana et al., 2012). As other bivalves, $R$. philippinarum are large organisms that burrow and forage for food on suspended particles with their siphons extruded far beyond the sediment-water interface (Campana et al., 2013a). As a consequence, the relative contribution of $\mathrm{dCu}_{\mathrm{PW}}$ to bioaccumulation through the incurrent siphon could be considered negligible.

On the other hand, the contribution of $\mathrm{pCu}_{\text {sed }}$ to copper bioaccumulation was strong and significant $(\rho=0.61, p<0.001, n=39$ ). These results indicate that both dissolved (only $\mathrm{dCu}_{\mathrm{OLW}}$ ) and particulate exposure pathways represent major contributors to copper uptake for this suspension feeder. Similar results were also obtained in other studies with the bivalves Scrobicularia plana (Kalman et al., 2014) and Tellina deltoidalis (Campana et al., 2013b) highlighting the importance of both uptake routes for the bioaccumulation kinetics.

\subsection{Relating growth rate and total net accumulation rate}

Growth rates are presented in Fig. 3. Growth rates in the control experiment did not vary significantly throughout the exposure $(H$-test $=$ $0.71 ; p=0.87)$ and organisms grew at an average rate of $0.5 \pm$ $0.3 \mathrm{mg} \mathrm{day}^{-1}$ (mean $\pm \mathrm{SD}$ ). Likewise, in the increasing exposure experiment, where the organisms were exposed to increasing copper

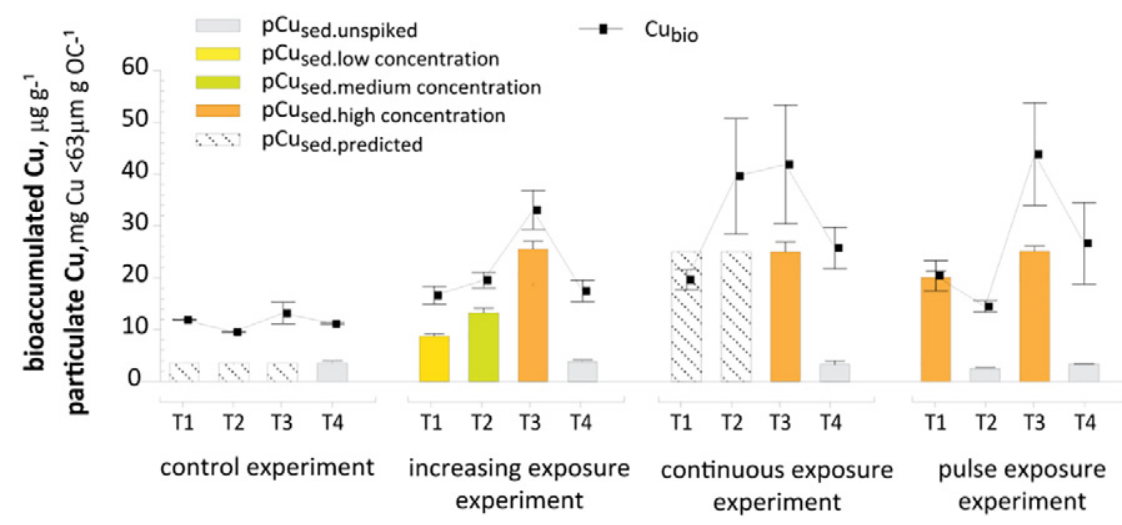

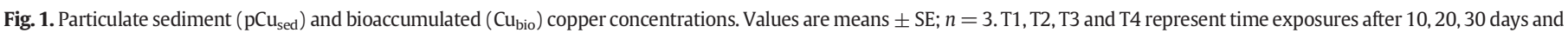
10-day recovery, respectively. 


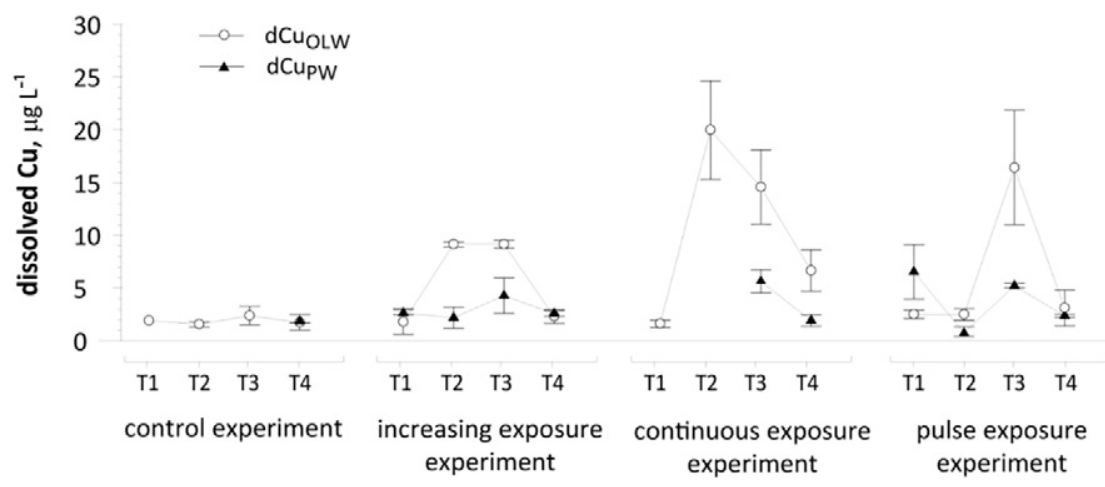

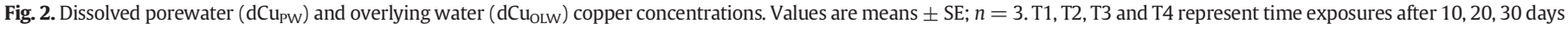
and 10 -day recovery, respectively.

concentrations growth rates did not change significantly. However, when they were allowed to recover, growth rate boosted significantly to $4.9 \mathrm{mg} \mathrm{day}^{-1}$ ( $F$-ratio $=20.25 ; p<0.001 ; \mathrm{df}=10$ ). The same pattern was observed in the continuous and pulse exposure experiments where again, growth rates did not show any significant variation but were significantly greater during the recovery period, $3.5 \mathrm{mg} \mathrm{day}^{-1}(F$-ratio $=$ 39.16; $p<0.001 ; \mathrm{df}=11)$ and $1.8 \mathrm{mg} \mathrm{day}^{-1}($ F-ratio $=6.52 ; p<$ 0.05 ; $\mathrm{df}=11$ ), respectively.

These data show that different exposure scenarios had no significant effect on growth, considering the time frame and the concentrations chosen, but when the exposure was removed the organisms began to recover as indicated by their growth rates being up to one order of magnitude greater compared to the control. Nevertheless, the degree of this recovery is affected by the type of exposure applied during the first 30 days. Post hoc LSD analyses indicated that growth rates during the recovery period were significantly different among experiments ( $F$ ratio $=37.84 ; p<0.001 ; \mathrm{df}=10)$. The organisms exposed to a pulsed impact recovered at much lower rate, while, those exposed to increasing copper concentrations show the highest stimulation of the growth rate. It is worthwhile to highlight that, without considering the recovery data, the results did not show any particular adverse effect on growth caused by the different exposures but it is the extent of the effect on the resilience capacity that revealed how the organisms were affected by the different type of exposure.

Fig. 3 also shows the total copper net accumulation rates. In the control experiment organisms maintained a net accumulation rate close to zero $\left(-0.07 \pm 0.08 \mu \mathrm{g} \mathrm{g}^{-1}\right.$ day $^{-1}$; mean $\left.\pm \mathrm{SD}\right)$ without any significant variation $(H$-test $=6.0 ; p>0.05)$. Likewise, in the increasing exposure experiment the accumulation rate showed positive values, without any significant variation, during the first 30 days of the exposure but switched to a significant negative value during the recovery period ( $H$-test $=8.74 ; p<0.05)$. Similarly, in the continuous exposure experiment the organisms accumulated copper at the same rate during the exposure but significantly eliminated the metal during the recovery period ( $F$-ratio $=5.15 ; p<0.05 ; \mathrm{df}=11$ ). The same pattern was observed for the pulsed exposure experiment where the bivalves accumulated copper when exposed to spiked sediment and they released it when the exposure was removed ( $F$-ratio $=7.75 ; p<0.01$; $\mathrm{df}=11$ ). In this experiment the accumulation rate corresponding to the second pulse (T3) represented the highest net accumulation rate $\left(2.6 \mu \mathrm{g} \mathrm{g}^{-1-}\right.$ day $^{-1}$ ) observed among all treatments.

The significant negative correlation found between growth and total copper accumulation rates $(\rho=-0.73, p<0.01, n=16)$ indicated a clear negative relationship between these two variables, which most likely depended on the duration of the recovery period. The decrease of the absolute copper content in the organisms (Fig. S2 of the Supporting Information) during the recovery period for each exposure showed that the dilution factor associated to the increased growth was not the main cause of the negative correlation observed and that copper elimination and growth were strongly related.

There are not many studies that attempt to analyse the relationship between metal accumulation rates and sublethal effects on aquatic organisms. Campana et al. (2013b) and Campana et al. (2015) studied the effect on growth and the accumulation kinetics of copper in the deposit-feeder bivalve Tellina deltoidalis exposed to spiked sediments during 41 days. They calculated an $\mathrm{EC}_{50}$ value for growth of $10.5 \mathrm{mg}$

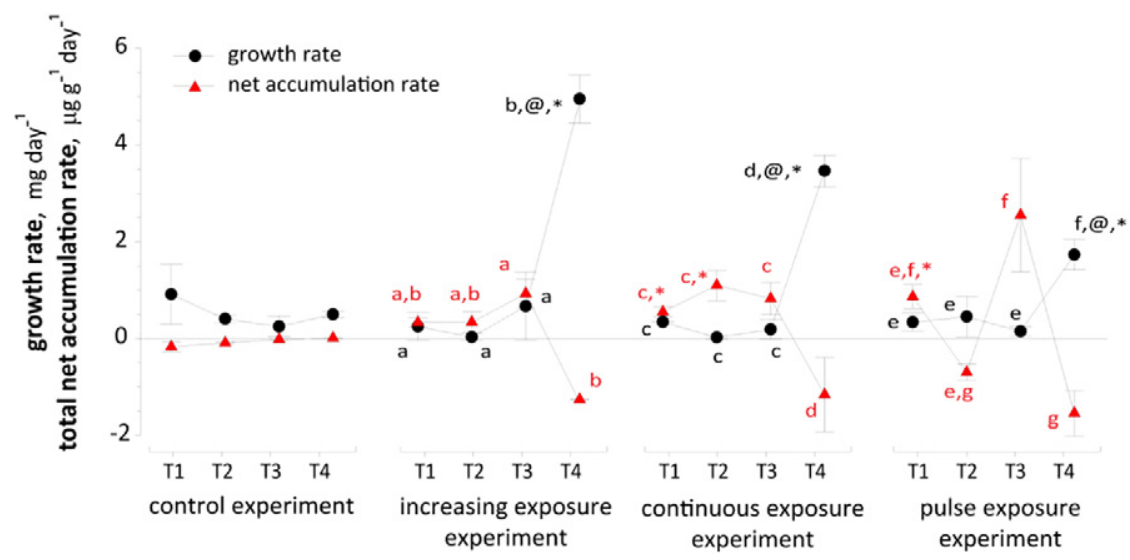

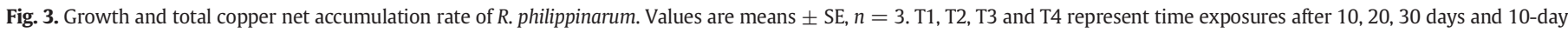

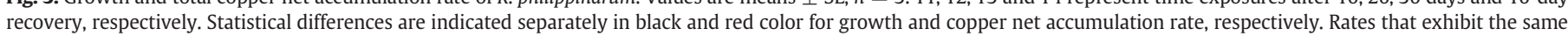
letter are not statistically different; * and ${ }^{@}$ represent statistical difference from the control and between treatments, respectively, at the same exposure time. 
$\mathrm{Cu}<63 \mu \mathrm{m} \mathrm{g}^{-1}$ OC. Yet, according to our results, we did not observe any effect on growth when individuals of $R$. philippinarum were exposed to more than twice this concentration. Comparing the net accumulation rates of both species exposed to similar copper concentrations, $R$. philippinarum accumulated copper at a rate approximately 20 times lower than T. deltoidalis. Accumulation rates of $R$. philippinarum were more comparable to those calculated by Kalman et al. (2015) for the bivalve Scrobicularia plana that, exposed to a metal mixture of field collected sediments (with copper concentrations between 15 and 2310 $\mu \mathrm{g} \mathrm{g}^{-1}$ ), showed accumulation rates that ranged between 1.01 and $1.86 \mu \mathrm{g} \mathrm{Cu} \mathrm{g}^{-1}$ day $^{-1}$. These data indicated that $R$. philippinarum and potentially, $S$. plana, can be considered weak net copper bioaccumulators compared to T. deltoidalis.

\subsection{Characterization of the total net accumulation rate}

Metal toxicokinetics is a dynamic process that depends on both the magnitude and the duration of the exposure; however, as recently considered by other authors (Casado-Martinez et al., 2010; Kalman et al., 2015; Rainbow and Luoma, 2011b), the significance of the critical body threshold hypothesizes that a metabolically available fraction, instead of the total body residue, is responsible for the toxic effect and the detoxification/elimination capability of the organisms strongly affects the amount of metal bioaccumulated in this fraction. The percentages of the NCD subcellular fraction and BDM and BAM pools are shown in Fig. 4. Each percentage is represented as positive or negative depending on its specific net rate indicating a copper accumulation or elimination from the specific pool, respectively. The algebraic sum of the rates makes up for the total net accumulation rate. As in other studies (Cooper et al., 2010; Liu et al., 2013; Wallace et al., 2003), NCD fraction was not included in either of the BDM or BAM pool because the toxicological role of this fraction is not clearly understood.

Overall, in the control experiment the organisms eliminated copper mostly from the BDM pool that represented the major contributor to the total accumulation rate (40 to $61 \%$ ), followed by the NCD fraction, (31\%) which was the only compartment where copper was accumulated starting at T2 (up to 58\%), and the BAM pool (2 to 32\%). In the increasing exposure experiment, most of copper that the organisms bioaccumulated when exposed to spiked sediments was detoxified in the BDM pool. The degree of detoxification ranged from between 50 and $68 \%$ and only 7 to $4 \%$ was metabolically available associated with the BAM pool. The NCD fraction accounted for 28 to $42 \%$ of the total accumulation rate. During the recovery period $68 \%$ of copper was released from the BDM pool, $27 \%$ from NCD fraction and 5\% from BAM pool. The same pattern was observed in the continuous and pulsed exposure experiments with very low variability in the proportional partitioning of copper among each compartment. During the continuous exposure experiment copper was principally associated with the BDM pool (62 to $65 \%$ ) and $73 \%$ released during the recovery period. NCD fraction accounted for 28 to $34 \%$ of copper that was bioaccumulated during continuous exposure while copper associated with the BAM pool ranged between 4 and $7 \%$. During the recovery period, 26\% was released from the NCD fraction but $1 \%$ was still metabolically available in the BAM pool.

In the pulsed exposure experiment percentages of copper associated with the BDM pool, NCD fraction and BAM pool ranged between 62 and $63 \%, 32$ to $36 \%$ and 2 to $5 \%$, respectively. During recoveries (following two pulsed exposures) copper eliminated from these same compartments accounted for 67 to $68 \%, 27$ to $29 \%$ and 2 to $6 \%$ of the total accumulation rate, respectively.

Because copper is an essential metal many organisms have evolved specific mechanisms to regulate its uptake coupled with detoxification storage and elimination strategies (Phillips and Rainbow, 1989). For example, a slow copper uptake and a fast efflux rate, as demonstrated for the amphipod Melita plumulosa (Campana et al., 2015; King et al., 2005), result in a low net accumulation rate. The net accumulation rates of this amphipod, exposed to sediment copper concentrations within the same range of those applied in this study, were of the same order of magnitude as for the net accumulation rate values observed for $R$. philippinarum. However, the comparison between the distribution of copper within BDM and BAM pools indicated that the organisms have developed different bioaccumulation strategies to deal with increasing external concentrations. In the amphipod, bioaccumulated copper was mainly associated with the BAM pool and increased along the $\mathrm{pCu}_{\text {sed }}$ gradient. The bivalve $R$. philippinarum detoxified most of bioaccumulated copper in the BDM pool while just a small amount of metal was allocated to the BAM pool. This appeared to be the same strategy adopted by the bivalve T. deltoidalis exposed to copper spiked sediments (Campana et al., 2015). In both bivalves total net accumulation rates increased linearly with $\mathrm{pCu}_{\text {sed, }}$, however, in $R$. philippinarum the rate increased seven times more slowly $\left(m=0.11 \pm 0.02 ; r^{2}=\right.$ $0.74 ; p<0.001)$ compared to T. deltoidalis $\left(m=0.79 \pm 0.08 ; r^{2}=\right.$ $0.93 ; p<0.001)$, where the slope $(m)$ represented the estimated net accumulation rate constant (mean $\pm \mathrm{SE}$ ) and was expressed in $\mathrm{g} \mathrm{OC}$ $\mathrm{g}^{-1}$ day $^{-1}$. Also, as reported for T. deltoidalis, R. philippinarum showed a significant linear relationship between the rate of copper accumulated in the BDM pool and $\mathrm{pCu}_{\text {sed }}\left(r^{2}=0.75 ; p<0.001\right)$.

\subsection{Contribution of the subcellular fractions to BDM and BAM pools}

When the uptake rate of an essential metal such as copper is beyond the metabolic requirements of the organism, the metal might bind to sites where it can cause toxic effects and must be detoxified, in a temporary or permanent form. Many metals induce the synthesis of

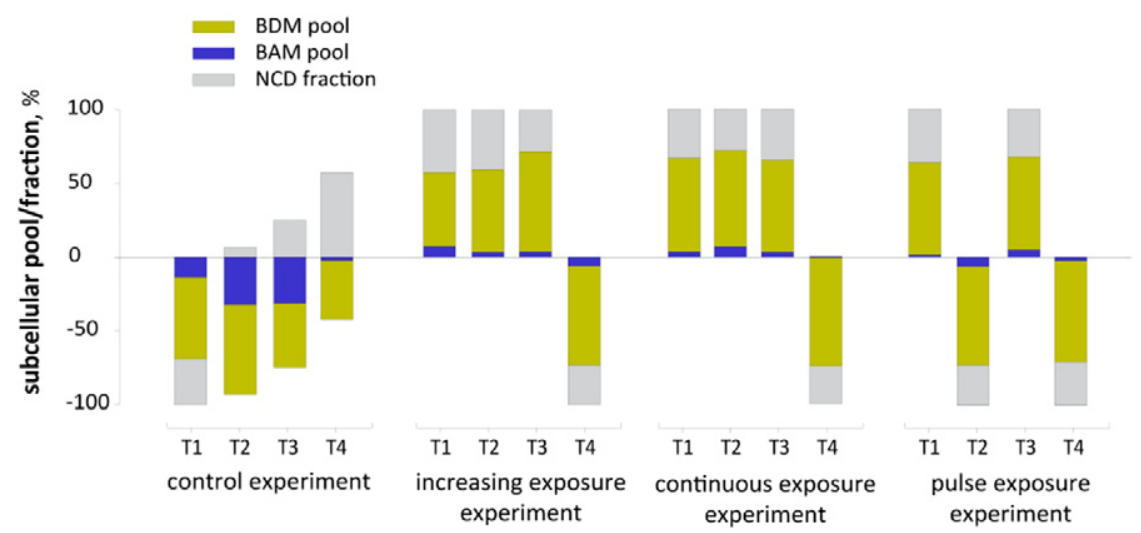

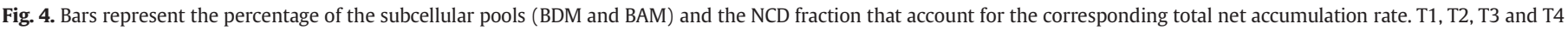

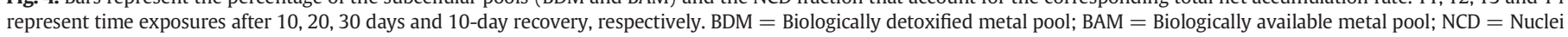
and cellular debris fraction. 
metallothioneins, low molecular weight cytosolic proteins that bind and detoxify metals intracellularly (Amiard et al., 2006; Geret et al., 2002) and also play and important role in the homeostasis of essential metals providing a reservoir (Viarengo and Nott, 1993). Following in the text, the rate of copper accumulated in the BDM and BAM pool was indicated as BDM rate and BAM rate, respectively. In R. philippinarum most of copper bioaccumulated in the BDM pool was detoxified by the metalbinding to metallothionein like proteins (Fig. 5a). In the control experiment copper was mainly eliminated from the MTLP fraction (percentages varied between 74 and 97\%). In all treatments the percentage of copper detoxified in the MTLP fraction during exposure ranged between 76 and 93\%, 81-90\% and 59-91\% for the increasing, continuous and pulsed exposure experiments, respectively. Consistently, as observed for the control, copper was largely released from the MTLP fraction during the recovery period. The rate of copper accumulation in the BDM pool was found inversely and significantly correlated to growth rate $(\rho=-0.74, p<0.01, n=16)$.

Another way for aquatic organisms to detoxify metals is to store them in form of insoluble granules or deposits of several types (Brown, 1982; Hopkin, 1989; Marigómez et al., 2002; Phillips and Rainbow, 1989). Type B metal-rich granules have been described as heterogeneous granules containing sulphur in association with metals such as copper and zinc. In R. philippinarum a very limited amount of copper was associated with MRG fraction (Fig. 5a) and the higher percentages were observed at $\mathrm{T} 1$ for all experiments reaching 24,19 and $41 \%$ for increasing, continuous and pulsed exposure, respectively. As was the case for the juvenile $R$. philippinarum tested in this study, Wallace et al. (2003) found that Macoma baltica clams smaller than $0.3 \mathrm{~g}$ wet weight did not have cadmium associated with the MRG fraction. On the other hand, Campana et al. (2015) reported that in adult individuals of $T$. deltoidalis $85 \%$ of copper was detoxified in the MRG fraction and only $15 \%$ in the MTLP fraction; the partitioning eventually reached $50-50 \%$ at the highest copper bioaccumulation concentrations. According to these results, it can be hypothesized that maturity can affect detoxification strategy of bivalves.

The BAM pool represents the toxic target of metals because it contains the most important and dynamic subcellular fractions in the organisms, including ORG and HDP fraction. The rate of copper accumulation in the BAM pool rate was inversely correlated to growth rate $(\rho=$ $-0.65, p<0.05, n=16$ ). Significant increase in this pool was only observed in the pulsed exposure experiment (Fig. 5b). In the control experiment the ORG fraction accounted for the most of the copper accumulated in the BAM pool but its percentage varied inconsistently in the other experiments as the HDP fraction. Overall, the contribution of each fraction to the BAM rate did not show any clear pattern.

\subsection{Implications for growth}

The results of this study led to two evident conclusions. First, independently of the exposure scenario sublethal concentrations of copper induced a large stimulatory effect on growth during the recovery period, as associated with significant negative net accumulation rate values. The magnitude of this effect exceeded by tenfold that reported for the control group. It might be possible that this large stimulatory effect is caused by an age-factor, juveniles being more capable of an overcompensation compared to adult individuals (e.g. Hoare et al. (1995)).

When organisms are exposed to toxicants an alteration in their allocation energy pattern is expected. This implies that if additional energy is invested in one physiological process (e.g. growth, reproduction, metabolism) less energy will be available for others, assuming a stable energy intake (Calow and Sibly, 1990). In this study growth rate was inversely (significantly) correlated to net copper accumulation rate and to BDM and BAM rates as well. This suggested a change in the allocation energy pattern determined by an increase of the energy expenditure on detoxification and homeostasis processes to maintain fitness at a constant level and deal with the external impact, at the same time reducing the energy available for growth. Once the stress due to copper was removed this energy could have been again devoted to enhance growth in an effort to anticipate sexual maturity and ensure a successful reproduction in the event of a new stress.

Hoare et al. (1995) observed a similar behaviour in M. edulis where juveniles' growth rate increased after the individuals were exposed to copper treatments during the embryo stage. However, despite the faster growth rate, the survival was greatly reduced through metamorphosis
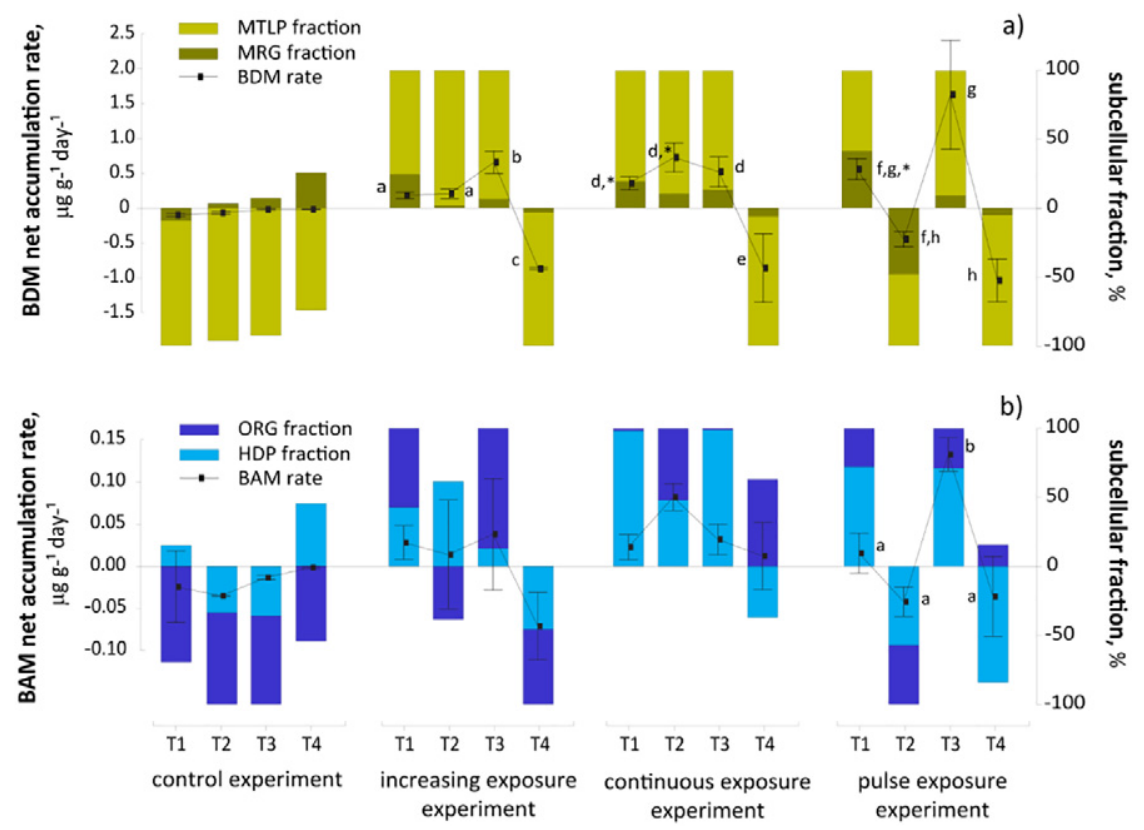

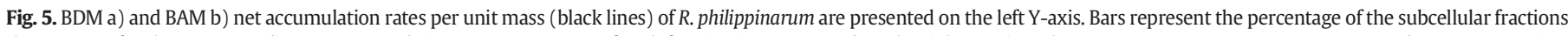

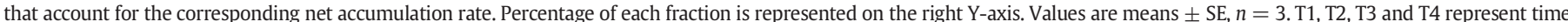

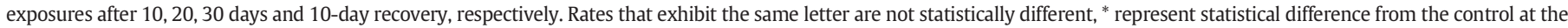

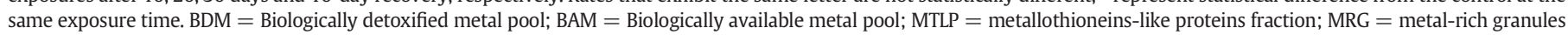
fraction; $\mathrm{ORG}=$ heavy organelles fraction; HDP = heat-denaturate proteins fraction. 
to juvenile stage. At the end, the stimulation of the growth had adverse long-reaching consequences on the fitness of the individuals and eventually at the population level.

The same issue arises when considering the second conclusion of this study. The stimulation of the growth rate seemed to be exposurerelated. The pulsed impact led to a significantly lower compensation response in the organisms compared to other exposures; on an individual and short-term basis this result suggested that pulsed exposures have a more adverse effect compared to increased or continuous exposure impacts. Nonetheless, could this lower stimulation be considered a positive outcome on a long-term scenario?

\section{Acknowledgments}

This work was funded by the Program CAPES-PDSE (7333/13-7) through a PhD scholarship to L. Santana. We thank M ${ }^{\mathrm{a}}$ Carmen Agullo for her assistance with metal analysis and the OPECAM Unit of the Instituto de Ciencias Marinas de Andalucía (CSIC) for their help with the sediment collection and technical support.

\section{Appendix A. Supplementary data}

Supplementary data to this article can be found online at http://dx. doi.org/10.1016/j.scitotenv.2017.03.020.

\section{References}

Ahlf, W., Drost, W., Heise, S., 2009. Incorporation of metal bioavailability into regulatory frameworks-metal exposure in water and sediment. J. Soils Sediments 9, 411-419.

Amachree, D., Moody, A.J., Handy, R.D., 2013. Comparison of intermittent and continuous exposures to cadmium in the blue mussel, Mytilus edulis: accumulation and sublethal physiological effects. Ecotoxicol. Environ. Saf. 95, 19-26.

Amiard, J.C., Amiard-Triquet, C., Barka, S., Pellerin, J., Rainbow, P.S., 2006. Metallothioneins in aquatic invertebrates: their role in metal detoxification and their use as biomarkers. Aquat. Toxicol. 76, 160-202.

Bat, L., Raffaelli, D., 1998. Sediment toxicity testing: a bioassay approach using the amphipod Corophium volutator and the polychaete Arenicola marina. J. Exp. Mar. Biol. Ecol. 226, 217-239

Brown, B.E., 1982. The form and function of metal-containing "granules" in invertebrate tissues. Biol. Rev. 57, 621-667.

Calow, P., Sibly, R.M., 1990. A physiological basis of population processes: ecotoxicological implications. Funct. Ecol. 4, 283-288.

Campana, O., Simpson, S.L., Spadaro, D.A., Blasco, J., 2012. Sub-lethal effects of copper to benthic invertebrates explained by sediment properties and dietary exposure. Environ. Sci. Technol. 46, 6835-6842.

Campana, O., Rodríguez, A., Blasco, J., 2013a. Evaluating the suitability of Hydrobia ulvae as a test species for sediment metal toxicity testing applying a tissue residue approach to metal mixtures in laboratory and field exposures. Chemosphere 91 (8), $1136-1145$

Campana, O., Blasco, J., Simpson, S.L., 2013b. Demonstrating the appropriateness of developing sediment quality guidelines based on sediment geochemical properties. Environ. Sci. Technol. 47, 7483-7489.

Campana, O., Taylor, A.M., Blasco, J., Maher, W.A., Simpson, S.L., 2015. Importance of subcellular metal partitioning and kinetics to predicting sublethal effects of copper in two deposit-feeding organisms. Environ. Sci. Technol. 49, 1806-1814.

Casado-Martinez, C., Smith, B.D., Luoma, S.N., Rainbow, P.S., 2010. Metal toxicity in a sediment-dwelling polychaete: threshold body concentrations or overwhelming accumulation rates? Environ. Pollut. 158, 3071-3076.

Chong, K., Wang, W.-X., 2000. Bioavailability of sediment-bound $\mathrm{Cd}, \mathrm{Cr}$ and $\mathrm{Zn}$ to the green mussel Perna viridis and the Manila clam Ruditapes philippinarum. J. Exp. Mar. Biol. Ecol. 255, 75-92.

Cooper, S., Hare, L., Campbell, P.G., 2010. Subcellular partitioning of cadmium in the freshwater bivalve, Pyganodon grandis, after separate short-term exposures to waterborne or diet-borne metal. Aquat. Toxicol. 100, 303-312.

Croteau, M.-N., Luoma, S.N., 2009. Predicting dietborne metal toxicity from metal influxes. Environ. Sci. Technol. 43, 4915-4921.

DeForest, D.K., Meyer, J.S., 2015. Critical review: toxicity of dietborne metals to aquatic organisms. Crit. Rev. Environ. Sci. Technol. 45, 1176-1241.
Delgado, M., Pérez-Camacho, A., 2007. Comparative study of gonadal development of Ruditapes philippinarum (Adams and Reeve) and Ruditapes decussatus (L.) (Mollusca: Bivalvia): influence of temperature. Sci. Mar. 71, 471-484.

Fan, W., Wang, W.-X., 2001. Sediment geochemical controls on Cd, Cr, and Zn assimilation by the clam Ruditapes philippinarum. Environ. Toxicol. Chem. 20, 2309-2317.

Fukunaga, A., Anderson, M.J., 2011. Bioaccumulation of copper, lead and zinc by the bivalves Macomona liliana and Austrovenus stutchburyi. J. Exp. Mar. Biol. Ecol. 396, 244-252.

Subcellular accumulation and detoxification of metals in aquatic animals. In: George, S.G., W. B. C, Vernberg, A., Thurberg, F.P., Vernberg, F.J. (Eds.), Physiological Mechanisms Of Marine Pollutant Toxicity. Academic Press, New York, pp. 3-52.

Geret, F., Serafim, A., Barreira, L., João Bebianno, M., 2002. Response of antioxidant systems to copper in the gills of the clam Ruditapes decussatus. Mar. Environ. Res. 54, 413-417.

Giguère, A., Couillard, Y., Campbell, P.G.C., Perceval, O., Hare, L., Pinel-Alloul, B., Pellerin, J., 2003. Steady-state distribution of metals among metallothionein and other cytosolic ligands and links to cytotoxicity in bivalves living along a polymetallic gradient. Aquat. Toxicol. 64, 185-200.

Hoare, K., Davenport, J., Beaumont, A.R., 1995. Effects of exposure and previous exposure to copper on growth of veliger larvae and survivorship of Mytilus edulis juveniles. Mar. Ecol. Prog. Ser. 120, 163-168.

Hopkin, S.P., 1989. Ecophysiology of Metals in Terrestrial Invertebrates. Springer, Netherlands.

Hutchins, C.M., Teasdale, P.R., Lee, S.Y., Simpson, S.L., 2008. Cu and Zn concentration gradients created by dilution of $\mathrm{pH}$ neutral metal-spiked marine sediment: a comparison of sediment geochemistry with direct methods of metal addition. Environ. Sci. Technol. 42, 2912-2918.

Kalman, J., Smith, B.D., Bury, N.R., Rainbow, P.S., 2014. Biodynamic modelling of the bioaccumulation of trace metals ( $\mathrm{Ag}$, As and $\mathrm{Zn}$ ) by an infaunal estuarine invertebrate, the clam Scrobicularia plana. Aquat. Toxicol. 154C, 121-130.

Kalman, J., Bonnail-Miguel, E., Smith, B.D., Bury, N.R., Rainbow, P.S., 2015. Toxicity and the fractional distribution of trace metals accumulated from contaminated sediments by the clam Scrobicularia plana exposed in the laboratory and the field. Sci. Total Environ. 506-507, 109-117.

King, C.K., Simpson, S.L., Smith, S.V., Stauber, J.L., Batley, G.E., 2005. Short-term accumulation of $\mathrm{Cd}$ and $\mathrm{Cu}$ from water, sediment and algae by the amphipod Melita plumulosa and the bivalve Tellina deltoidalis. Mar. Ecol. Prog. Ser. 287, 177-188.

Liu, F., Rainbow, P.S., Wang, W.X., 2013. Inter-site differences of zinc susceptibility of the oyster Crassostrea hongkongensis. Aquat. Toxicol. 132-133, 26-33.

Marigómez, I., Soto, M., Cajaraville, M.P., Angulo, E., Giamberini, L., 2002. Cellular and subcellular distribution of metals in molluscs. Microsc. Res. Tech. 56, 358-392.

Phillips, D.J.H., Rainbow, P.S., 1989. Responses of marine organisms to pollutants strategies of trace metal sequestration in aquatic organisms. Mar. Environ. Res. 28, 207-210.

Rainbow, P., 2002. Trace metal concentrations in aquatic invertebrates: why and so what? Environ. Pollut. 120, 497-507.

Rainbow, P.S., Luoma, S.N., 2011a. Metal toxicity, uptake and bioaccumulation in aquatic invertebrates-modelling zinc in crustaceans. Aquat. Toxicol. 105, 455-465.

Rainbow, P.S., Luoma, S.N., 2011b. Trace metals in aquatic invertebrates. Environmental Contaminants in Biota: Interpreting Tissue Concentrations. Taylor and Francis Books Boca Raton, FL, USA, pp. 231-252.

Rainbow, P.S., Liu, F., Wang, W.X., 2015. Metal accumulation and toxicity: the critical accumulated concentration of metabolically available zinc in an oyster model. Aquat. Toxicol. 162, 102-108.

Simpson, S.L., King, C.K., 2005. Exposure-pathway models explain causality in whole sediment toxicity tests. Environ. Sci. Technol. 39, 837-843.

Simpson, S.L., Angel, B.M., Jolley, D.F., 2004. Metal equilibration in laboratorycontaminated (spiked) sediments used for the development of whole-sediment toxicity tests. Chemosphere 54, 597-609.

Simpson, S.L., Batley, G.E., Hamilton, I.L., Spadaro, D.A., 2011. Guidelines for copper in sediments with varying properties. Chemosphere 85, 1487-1495.

Strom, D., Simpson, S.L., Batley, G.E., Jolley, D.F., 2011. The influence of sediment particle size and organic carbon on toxicity of copper to benthic invertebrates in oxic/suboxic surface sediments. Environ. Toxicol. Chem. 30, 1599-1610.

Taylor, A.M., Maher, W.A., 2012. Exposure-dose-response of Anadara trapezia to metal contaminated estuarine sediments. 2. Lead spiked sediments. Aquat. Toxicol. 116117, 79-89.

Viarengo, A., Nott, J.A., 1993. Mechanisms of heavy metal cation homeostasis in marine invertebrates. Comp. Biochem. Physiol. C 104, 355-372.

Vijver, M.G., Van Gestel, C.A.M., Lanno, R.P., Van Straalen, N.M., Peijnenburg, W.J.G.M., 2004. Internal metal sequestration and its ecotoxicological relevance: a review. Environ. Sci. Technol. 38, 4705-4712.

Wallace, W., Lee, B., Luoma, S., 2003. Subcellular compartmentalization of $\mathrm{Cd}$ and $\mathrm{Zn}$ in two bivalves. I. Significance of metal-sensitive fractions (MSF) and biologically detoxified metal (BDM). Mar. Ecol. Prog. Ser. 249, 183-197. 